\title{
Aggregated Economic Analysis of the Brazilian Electricity Distribution Companies Using a Regulated Market Economic Model
}

\author{
Carolina Cortez · Benedito Donizeti Bonatto · Hector Arango · Miguel Castilla
}

Received: date / Accepted: date

\begin{abstract}
While most of the research work in the field of electrical engineering was aroused by the scientific challenges to be overcome, it is fair to recognize that the practical importance of engineering hinges on its economic impact on the market, the whole society and the environment. Thus, nowadays economic modeling, analysis and optimization of the electricity market is of the utmost significance.This work presents an aggregated economic analysis of the Brazilian electricity distribution companies using an economic model of a regulated market. The fundamental agents (consumer, power utility, government, society) are represented in the TAROT - Optimized Tariff Model, which is applied to the majority of the distribution companies in Brazil, based on public real data available from ANEEL - the Brazilian electrical energy regulatory agency. This reveals the economic flows in the regulated market of each company, and also presents their financial status in terms of over-investments or under investments compared to optimal investments and positive, negative or zero economic value added of each company. Moreover, the model analysis show the socio-economical
\end{abstract}

\section{Cortez}

KIOS Research and Innovation Center of Excellence and Department of Electrical and Computer Engineering, University of Cyprus, 1 Panepistimiou Avenue, 2109 Aglantzia, Nicosia, Cyprus

E-mail: ccorte@ucy.ac.cy

\section{B. D. Bonatto and $\mathrm{H}$. Arango}

Advanced Power Technologies Innovations in Systems and Smart Grids Group - aPTIs-SG ${ }^{2}$ and Federal University of Itajuba, Av. BPS, 1303 - Bairro Pinheirinho, Itajuba, MG, Brazil

E-mail: bonatto@unifei.edu.br E-mail: hector.arango1935@gmail.com

M. Castilla

Universitat Politècnica de Catalunya - Escola Politècnica Superior d'Enginyeria de Vilanova i la Geltru, Avda. Victor Balaguer, s/n, 08800 Vilanova i la Geltru (Barcelona) - Spain

E-mail: miquel.castilla@upc.edu welfare added to society in face of different optimization objectives.

Keywords Economic Market Model - Optimized Tariff . Regulation · Power Distribution Company · Optimization

\section{Introduction}

The deregulation of electricity sector in Brazil was mainly driven by the necessity of attracting private capital to invest on infrastructure, as an attempt to make up for the scarcity of public resources in the early 90s (Arango et al. (2006)). Presently, at the 20th anniversary of ANEEL, the Brazilian electrical energy regulatory agency, it raises the questions regarding the changes implemented by the authorities and electricity market agents and their consequences. As already known, the deregulation process was not straightforward and adjustments had to be made along the way. By the mid of 2001 an energy crises took place and most part of the country had to join a national plan for rationing energy consumption. The crises was intensified due to the drought that reduced water levels at hydroelectric dams. However it became very clear that the regulation's structure did not well provide appropriate conditions for attracting investment on power generation (Pereira et al. (2004)).

In response to these events, the new government in 2003 reformulated the institutional model of the electricity sector and new rules were created to guarantee the expansion of power generation. The role of the Distribution Companies (DisCos) becomes a key factor in this new structure, since they must predict and contract the amount of required energy to supply their consumer market five years in advance through bilateral contracts which, in the big picture, works as the main financier of the expansion of power generation and increases the reliability of the sector due to a better planning of the expansion of the generation. However, on 
the other hand, the DisCos are exposed to the risks associated with forecasting, long term contracts and the penalties in cases of subcontracting (Homrich et al. (2012); Alvarez (2007); Medina Macaira et al. (2016); Jardini et al. (2002)).

Despite the liberalization and the introduction of market rules, especially in the generation segments, the electricity transmission and distribution continued to function as natural monopolies and, for this reason, price regulation became very important as it restrains any power monopoly abuse. In this context, one of the most relevant aspects of the recent reforms introduced in the electricity power sector is the search for a price model that preserves the interests of consumers, guarantees the profitability of investors and stimulates sector efficiency (Pereira et al. (2004); Arango et al. (2008); Pereira and de Almeida (2013); Pereira et al. (2015); Cortez et al. (2018a,b); Arango et al. (2019); Cullmann and Nieswand (2016); Scalzer et al. (2019); Costa et al. (2019); Arango et al. $(2017,2011)$ ).

Intensive studies have been done towards the best price model for the retail market. The efforts show that implementing rules to simulate a competitive market in a monopoly environment is a big challenge with no global answer (Joskow (2008)). The purpose of this paper is to provide an economic overview of the utility companies in Brazil using the economic model of the regulated electricity market called TAROT (Optimized Tariff). What this paper seek to answer is if the regulatory framework designed for the distribution power system in Brazil is assuring the maximization of the social welfare produced by the activity. Are the designed rules allowing the system to evolve itself? Are the Discos investing efficiently in their power grids? Does the shareholder remuneration signal an attractiveness to the activity?

The approached used here is based on real data applied in an economic model based on the same regulatory premises adopted by ANEEL. In Section 2 it is briefly presented the regulatory mainframe and the regulated economic market model (TAROT) applied for the DisCos. Section 3 shows the financial regarding the Brazilian DisCos and it is followed by the results in Section 4 and the conclusions in Section 5.

\section{An Economic Market Model for the Regulated Electricity Distribution Activity}

The electrical power system in Brazil consists of about 52 DisCos and in order to create a standard and establish general procedures for calculating the energy price, ANEEL created the Tariff Regulation Procedures (PRORET) (ANEEL (2016)). This document, which has a normative character, consolidates the rules to determine the energy prices for the retail market. In general terms, the prices are reviewed periodically within four or five years, depending on the concession contract of the DisCos. The regulation methodology defines the electricity tariff, which is readjusted every

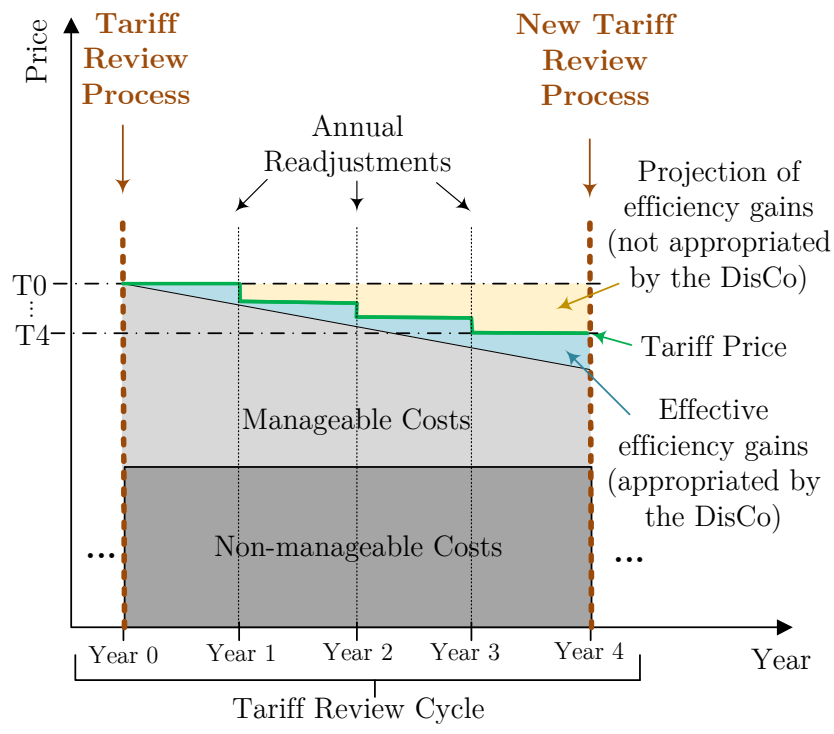

Fig. 1 Tariff Review Process (Cortez (2018)).

year to guarantee the maintenance of the economic and financial balance of the utility and to avoid that the energy price would suffer the corrosion of the inflationary process. Figure 1 illustrates the tariff revision and tariff readjustment processes in which an utility company has to undergo in order to obtain the energy price for its retail market.

The tariff review process starts at Year 0 and it happens in two stages. First, the regulator determines the tariff at a TO level through the process of tariff re-positioning. The second step is to design efficiency gains and productivity goals for the respective tariff cycle (Year 0 to Year 4), and from these values the regulator defines the $X$ Factor. Productivity gains from market growth and reduction of operational costs achieved by efficient management are appropriated annually by the DisCo. However, Factor $X$ reduces the tariff annually to protect the consumer by encouraging the DisCo towards efficiency. In Year 4 the DisCo is submitted to a new tariff review process (some contracts stipulate 5 year cycles).

\subsection{TAROT Model - Optimized Tariff}

The TAROT model was developed to represent a DisCo in a simple way in order to capture the essential aspects of its economic and financial performance (Arango et al. (2008); Pereira et al. (2015)). Illustrated in Fig. 2, the TAROT model with the economic flows in a regulated electricity market, presents the main structures and the transactions carried out among the stakeholders of the electricity market: utility, government and consumers. The model places the distribution activity in an economic modern perspective of aggregated economic value for the society, expressed by EWA (Economic Welfare Added) (Jehle and Reny (2001)). A portion of the EWA relates to the consumers surplus by the $E C A$ 


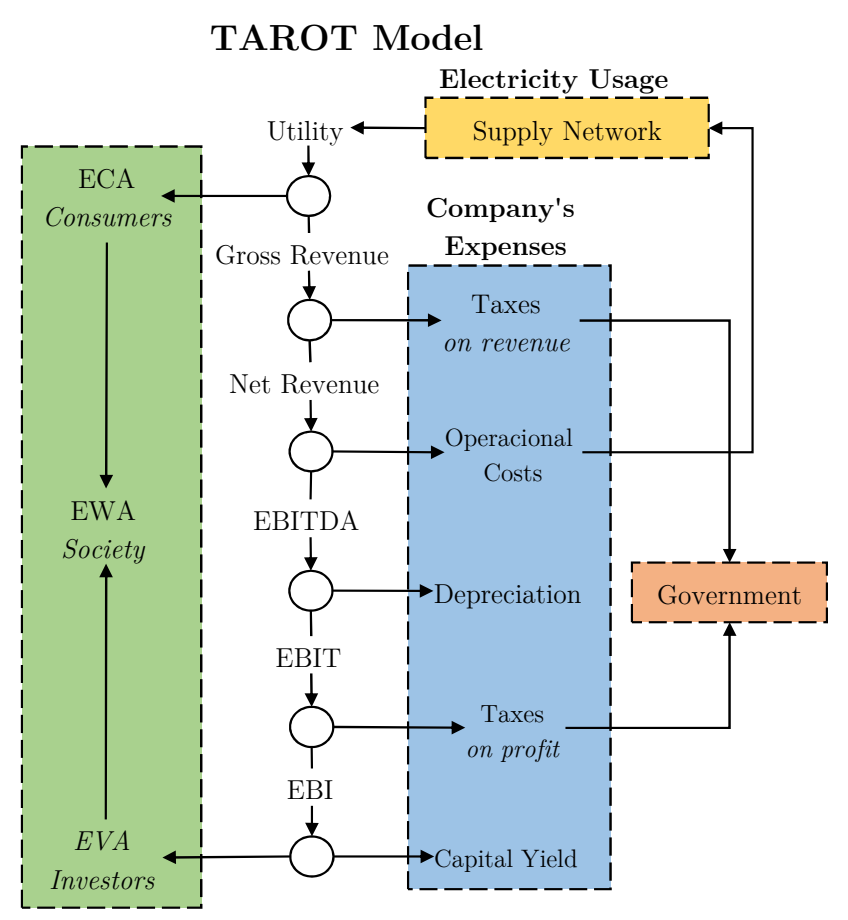

Fig. 2 TAROT (Optimized Tariff) model with the economic flows in a regulated electricity market. Adapted from (Arango et al. (2008)).

(Economic Consumers Added) and another portion refers to the value added to the company, the EVA (trademark of Stern \& Stewart Co. for Economic Value Added).

The economic benefit of the consumer $(U)$, also known as utility or willingness of the consumer to pay for electricity, reflects the principles of eagerness $(a)$ and satiety $(b)$. Thus, it can be modeled by the following expression:

$U=a \cdot E-\frac{b}{2} \cdot E^{2} \quad[M R \$]$

where $E[M W h]$ represents the total amount of consumed electricity and $U[R \$]$ represents the electricity utility economic value for the customers.

In order to simplify, the model treats the energy as a product with a single tariff price $(T[R \$ / M W h])$. Therefore the DisCo, as the energy supplier to the consumer, has a gross revenue $(G R)$ calculate as forward:

$$
G R=T \cdot E \quad[M R \$]
$$

The consumer eagerness can be calculated as a function of the energy tariff $(T)$ and the demand-price elasticity of the electric energy consumption $(\varepsilon)$ :

$a=T \cdot \frac{1+\varepsilon}{\varepsilon} \quad\left[\frac{R \$}{M W h}\right]$ or $\quad\left[\frac{M R \$}{T W h}\right]$

The consumer satiety $(b)$ is calculated as follows:

$b=\frac{a-T}{E} \quad\left[\frac{R \$}{M M W h^{2}}\right]$ or $\left[\frac{M R \$}{T W h^{2}}\right]$

All the expenses of the company are deducted over its revenue. Under the Brazilian law, the taxation takes place on sales and on profit. The tax rate on sales $(\mu)$ varies according to the state of the country (based on the data collected it ranged from $15 \%$ to $35 \%)$. Yet, the rate on profit $(t=34 \%)$ is the same for the whole country (9\% CSSL and 25\% IRPJ). The company has also to cover its operational costs $(G)$ (Eq. $5)$ and depreciation $(D)$. At last, the invested capital must be remunerated $(Y)$. The rate of the remuneration $\left(r_{w}\right)$ is calculated according to the methodology used by ANEEL for WACC (Weighted Average Capital Cost) (ANEEL (2015)) and the invested capital is represented by the Regulatory Remuneration Base $(B)$.

$G=e \cdot E+p \cdot \frac{E^{2}}{B} \quad[M R \$]$

where $e$ is the coefficient of network operating costs in $[R \$ / M W h]$ and $p$ is the loss coefficient in $\left[R \$^{2} / M W h^{2}\right]$.

This assumption is obviously a simplifying approximation of what happens in practice. However, it allows an organized and methodical treatment of the subject in academy, power industry, regulatory personnel and hopefully, general consumers.

Another parameter that can be extract from the model is the Return Over Investment $(R O I)$ :

$R O I=\frac{E B I T D A}{B}$

where EBIT DA stands for Earnings Before Interest, Taxes, Depreciation and Amortization.

2.2 The regulatory optimization of the electricity market using TAROT

The regulatory goal is to maximize the socioeconomic welfare value created by the electricity market under the circumstances of natural monopoly. How to avoid abusive market power? How to guarantee the quality of the service in a fair way to the consumer and, at the same time, to ensure the financial survival of the DisCos?

The solution design by ANEEL and implemented in the model is based in two optimization principles. First the company expenses must be minimal, which require an optimal value for the network investment ( $B^{*}$ in Eq. 7), called by ANEEL as Prudent Investment. This optimization condition ensures that the company will neither be under-invested nor over-invested. Since the remuneration for the shareholder depends on the $B$ value, it would be expected that the regulated company could seek for unnecessary investment in order to increase its profit with low risk, since the WACC is guaranteed by regulatory contract. This measure also prevents network assets from being below of what is necessary for the proper operation and reliable functioning of the grid. 


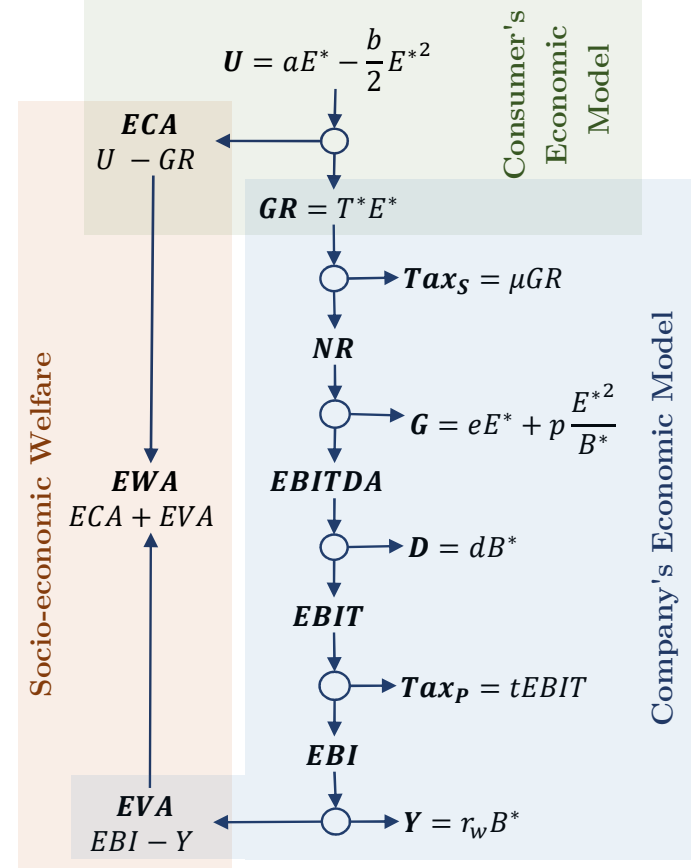

Fig. 3 Formulation of the TAROT model. Adapted from (Arango et al. (2008)).

From the TAROT model, the optimal investment $\left(B^{*}\right)$ can be calculated using Eq. 7.

$B^{*}=\sqrt{\frac{p}{k}} \cdot E \quad[R \$]$

where $B^{*}$ is the optimal investment, $k=d+r w /(1-t), d$ is the depreciation rate, $r w$ is the $W A C C$, and $t$ is the government tax on companys revenue.

Secondly, and at last, the energy tariff should represent a price that cover all the companies expenses and results in $E V A \geq 0$. For this, ANEEL determined that the EVA should be zero and it is said that the company is in Financial Economic Equilibrium (FEE), condition set at the beginning of the first year of the Tariff Review Process (Year 0 in Figure 1). The optimal tariff is then calculated by Eq. 8 .

$T^{*}=\frac{e+2 \cdot \sqrt{p \cdot k}}{1-\mu} \quad\left[\frac{R \$}{M W h}\right]$

By consequence, the model also provides the optimal energy transaction in the market:

$E^{*}=\frac{a-T^{*}}{b} \quad[M W h]$

The complete model formulation is presented in Fig. 3.

\subsection{The EVA optimization of the distribution company using TAROT}

Consider a virtual scenario where there is no regulation determining the price and thus limiting the electricity price or tariff. In this case, it is expected that the company would seek the maximization of its profit. Therefore, using the TAROT model is possible to state $E V A$ as a function of $E$ as in Eq. 10:

$E V A=\left(b-\mu b-\frac{p}{B}\right) E^{2}+(a-\mu a-e) E-k B$

The value for $E V A$ can be expressed as a second degree concave function. Thus, based on the consumer behaviour of the market, $E V A$ has a maximum value $E V A_{\max }$ for a given energy sale $E^{\prime}$, when $\partial E V A / \partial E=0$ resulting in Eq.(11):

$E^{\prime}=\frac{(1-\mu) a-e}{2 \cdot\left((1-\mu) b-\frac{p}{B}\right)}$

Thus the company can determine a tariff price $\left(T^{\prime}\right)$ using Eq. 9 that, due to the eagerness and satiety of its consumer market, will results into an amount of sold energy $\left(E^{\prime}\right)$ that maximizes its $E V A$.

Note that in the TAROT model, the consumer behaviour consider its eagerness $(a)$ and satiety $(b)$ and it is not inelastic as generally assumed.

\section{Economic Modeling and Simulation of the Electricity Market with real data}

Based on the technical and economic data published by ANEEL in the tariffs review processes of the Brazilians DisCos, it was developed a methodology to derive and adjust the input parameters for the use of TAROT model (Cortez (2018)). The Annual Tariff Adjustment (RTA) and Periodic Tariff Review processes (RTP) occur in dates defined in the concession legal agreements. Each tariff process is approved at a public board meeting of ANEEL and only then the tariffs are published by means of a Homologatory Resolution. The data from all of the tariff processes since 2013 are available in ANEEL website through the SPARTA worksheets (ANEEL (2017b)).

The name of the DisCos and the dates of the used tariff processing are shown in Table 1 . The company CERR have not undergone a tariff revision process since 2013, which makes it impossible to model the company due to lack of available data. CPFL Santa Cruz and ENERGISA SS are new DisCos resulted from recently grouping (ANEEL (2017b); Cortez (2018); ANEEL (2017a); Energisa Sul-Sudeste (2017)) and, therefore, do not have a tariff review, and can not be modeled as well. The TAROT model was applied to 49 Brazilian DisCos, among private and public companies. The data collection refers to a period of one year before the day of the tariff review process. The size of the utility companies in Brazil varies severely, and the graphic in Fig. 4 shows how much each company has of the national retail energy market. 
Table 1 Last tariff processes of the Brazilian Utility Companies (Cortez (2018)).

\begin{tabular}{|c|c|c|c|c|}
\hline \multirow{2}{*}{$\begin{array}{l}\text { Company } \\
\text { (State) }\end{array}$} & \multirow{2}{*}{$\begin{array}{c}\text { Process } \\
\text { Month } \\
\text { /Year }\end{array}$} & \multicolumn{2}{|c|}{ Tariff } & \multirow{2}{*}{$\begin{array}{c}\text { EVA } \\
\text { Real } \\
{[M R \$]}\end{array}$} \\
\hline & & $\begin{array}{r}\text { Real } \\
{[R \$]}\end{array}$ & $\begin{array}{l}\text { Optimal } \\
M W h]\end{array}$ & \\
\hline AES ELETROP. (SP) & $07 / 17$ & 447.14 & 439.68 & 150.75 \\
\hline CEB-DIS (DF) & $10 / 17$ & 485.99 & 495.94 & -33.55 \\
\hline CEEE-D (RS) & $11 / 17$ & 744.81 & 609.80 & 482.23 \\
\hline CELESC-DIS (SC) & $08 / 17$ & 431.86 & 409.47 & 257.39 \\
\hline CELG-D (GO) & $10 / 17$ & 605.61 & 555.31 & 294.48 \\
\hline CELPA (PA) & $08 / 17$ & 723.27 & 671.53 & 220.49 \\
\hline CELPE (PE) & $04 / 17$ & 484.53 & 476.93 & 49.34 \\
\hline CEMAR (MA) & $08 / 17$ & 698.57 & 617.98 & 219.03 \\
\hline CEMIG-D (MG) & $05 / 17$ & 371.14 & 417.42 & -723.65 \\
\hline CERR (RR) & - & - & - & - \\
\hline CHESP (GO) & $11 / 17$ & 828.19 & 712.12 & 5.43 \\
\hline COCEL (PR) & $06 / 17$ & 546.83 & 514.62 & 3.97 \\
\hline COELBA (BA) & $04 / 17$ & 469.96 & 461.64 & 47.20 \\
\hline COPEL-DIS (PR) & $06 / 17$ & 492.87 & 473.19 & 241.47 \\
\hline COPERALIANÇA (SC) & $08 / 17$ & 366.79 & 460.80 & -14.64 \\
\hline COSERN (RN) & $04 / 17$ & 469.91 & 461.34 & 20.81 \\
\hline CPFL Paulista (SP) & $04 / 18$ & 448.52 & 408.82 & 624.26 \\
\hline CPFL Piratininga (SP) & $10 / 17$ & 419.74 & 375.92 & 291.84 \\
\hline CPFL Santa Cruz (SP) & - & - & - & - \\
\hline DEMEI (RS) & $07 / 17$ & 700.64 & 665.39 & 2.86 \\
\hline DMED (MG) & $11 / 17$ & 492.67 & 408.20 & 12.15 \\
\hline EDP ES (ES) & $08 / 17$ & 463.14 & 436.96 & 120.98 \\
\hline EDP SP (SP) & $10 / 17$ & 406.98 & 349.40 & 431.35 \\
\hline EFLJC (SC) & $08 / 17$ & 736.75 & 707.94 & 0.22 \\
\hline EFLUL (SC) & $08 / 17$ & 412.42 & 418.46 & -0.29 \\
\hline ELEKTRO (SP) & $08 / 17$ & 457.95 & 425.63 & 260.93 \\
\hline ELETROB. AL (AL) & $09 / 17$ & 671.99 & 568.13 & 175.68 \\
\hline ELETROB. AM (AM) & $11 / 17$ & 616.12 & 524.98 & 59.24 \\
\hline ELETROB. PI (PI) & $09 / 17$ & 814.96 & 641.34 & 262.63 \\
\hline ELETROB. RR (RR) & $11 / 17$ & 621.91 & 542.74 & 38.74 \\
\hline ELETROCAR (RS) & $07 / 17$ & 674.88 & 639.70 & 1.96 \\
\hline ELFSM (ES) & $08 / 17$ & 706.55 & 643.44 & 15.43 \\
\hline ENEL CE (CE) & $11 / 17$ & 503.83 & 507.85 & -41.87 \\
\hline ENEL RJ (RJ) & $03 / 18$ & 724.60 & 670.39 & 222.74 \\
\hline ENERG.BO (PB) & $02 / 18$ & 609.27 & 545.97 & 18.25 \\
\hline ENERG. SS (SP-PR) & - & - & - & - \\
\hline ENERG. MG (MG) & $06 / 17$ & 600.61 & 577.86 & 14.67 \\
\hline ENERG. MS (MS) & $04 / 18$ & 599.78 & 581.11 & 33.76 \\
\hline ENERG. MT (MT) & $04 / 18$ & 667.88 & 628.92 & 134.32 \\
\hline ENERG. NF (RJ) & $06 / 17$ & 607.65 & 599.26 & -0.39 \\
\hline ENERG. PB (PB) & $08 / 17$ & 589.19 & 534.99 & 99.94 \\
\hline ENERG. SE (SE) & $04 / 17$ & 434.50 & 413.50 & 34.54 \\
\hline ENERG. TO (TO) & $07 / 17$ & 711.89 & 656.70 & 57.23 \\
\hline FORCEL (PR) & $08 / 17$ & 399.49 & 405.66 & -0.19 \\
\hline HIDROPAN (RS) & $07 / 17$ & 634.61 & 597.13 & 1.09 \\
\hline IENERGIA (SC) & $08 / 17$ & 477.42 & 465.12 & 1.17 \\
\hline LIGHT (RJ) & $03 / 18$ & 622.28 & 593.14 & 350.94 \\
\hline MUXENERGIA (RS) & $07 / 17$ & 546.80 & 505.16 & 1.25 \\
\hline RGE (RS) & $06 / 17$ & 469.77 & 450.95 & 82.73 \\
\hline RGE SUL (RS) & $04 / 17$ & 482.64 & 524.75 & -175.59 \\
\hline SULGIPE (SE) & $05 / 17$ & 543.55 & 558.75 & -2.94 \\
\hline UHENPAL (RS) & $05 / 17$ & 567.67 & 602.64 & -1.17 \\
\hline
\end{tabular}

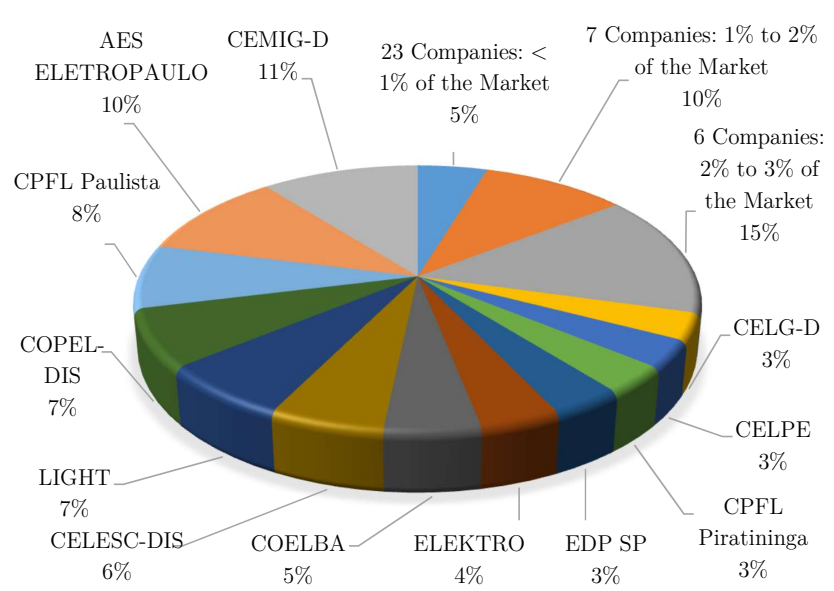

Fig. 4 Percentage of the energy consumed in the country (market share) for the regulated power distribution companies in Brazil.

In addition to the data extracted from the tariff review processes, it is also necessary to calculate the value of demandprice elasticity $(\varepsilon)$ of electric energy consumption. The value of $\varepsilon$ of each company was calculated using the definition of elasticity (Eq.12) and the companies' historical data of tariff and consumption from (ANEEL (2018)).

$\varepsilon=\frac{T}{E} \cdot \frac{\partial E}{\partial T}$

With the data collection from ANEEL (2017b) and using the formulation presented from Eq. 1 to 5 and Fig. 3 it is possible to calculate the TAROT economic parameters of each distribution company. It is also possible to optimize each DisCo using the regulatory assumptions from Section 2.2 .

\section{Economic Analysis of the Brazilian DisCos using TAROT}

\subsection{Tariff}

From the data collection and economic modeling using TAROT, the first analyses made, before optimization, was the evaluation of the electricity tariff $(T)$ paid by the final consumer. The values found for $T$ vary from $0.367[R \$ / k W h]$ to $0.828[R \$ / k W h]$ and the average is $0.547[R \$ / k W h]$. The average price in Euro is $0.106[€ / k W h]$ and in Dollar is $0.122[U S \$ / k W h]$.

On the other hand, the price paid by the companies for purchasing electrical energy from the power suppliers varies from $0.120[R \$ / k W h]$ to $0.245[R \$ / k W h]$ and the average value is $0.175[R \$ / k W h]$.

Once the companies were optimized, the electricity tariff average value calculated was $0.525[R \$ / M W h]$ varying from $0.349[R \$ / M W h]$ to $0.712[R \$ / k W h]$, showing that, in general, the tariffs applied by the companies are not optimal and surcharge the customer. 


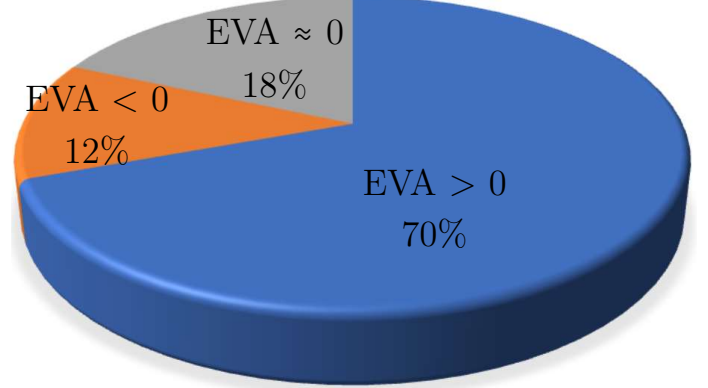

Fig. 5 Financial Economic Status of the Brazilian DisCos. For $E V A=$ 0 the company is in Financial Economic Equilibrium (FEE).

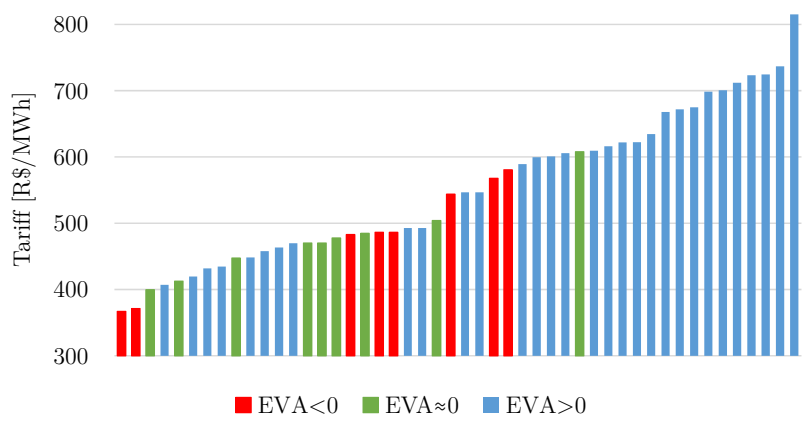

Fig. 6 Tariff and the Financial Economic Status $(E V A<0, E V A \approx 0$, $E V A>0$ ) of the DisCos.

\subsection{Financial Economical Status of the Brazilian DisCos}

The next evaluation made using TAROT is regarding the DisCos status of their EVA value before optimization considering that $E V A=0$ represents that the company is in Financial Economic Equilibrium (FEE). Using one year data for each company, it is resulted that 6 out of $49(12 \%)$ of the Brazilian DisCos presented a negative value for EVA. This means that the respective tariffs of these companies are not enough to cover all their expenses in the distribution business as it is being managed. There are 34 (69\%) companies with a tariff above from what is necessary (Fig. 5). At last, using a tolerance of $1 \%$ over the Gross Revenue for a status of $\operatorname{FEE}(E V A=0)$, it was found that $9(18 \%)$ companies are operating with $E V A$ close to zero.

The graphic in Fig. 6 shows the growing ordered value of the electricity tariff $(T)$ of each distribution company in Brazil with the correspondent financial economic status ( $E V A$ $0, E V A \approx 0, E V A>0$ ). Among the lowest tariffs, one can find companies with EVA positive, negative and close to zero. On the other hand, the companies with the highest tariffs are all with $E V A>0$. Therefore, one can question if the highest tariffs represents thoroughly higher costs or only higher profits.

To compare the companies performance is not an easy task since there is a big discrepancy between the size and many other parameters of them, as one can note from Fig. 4

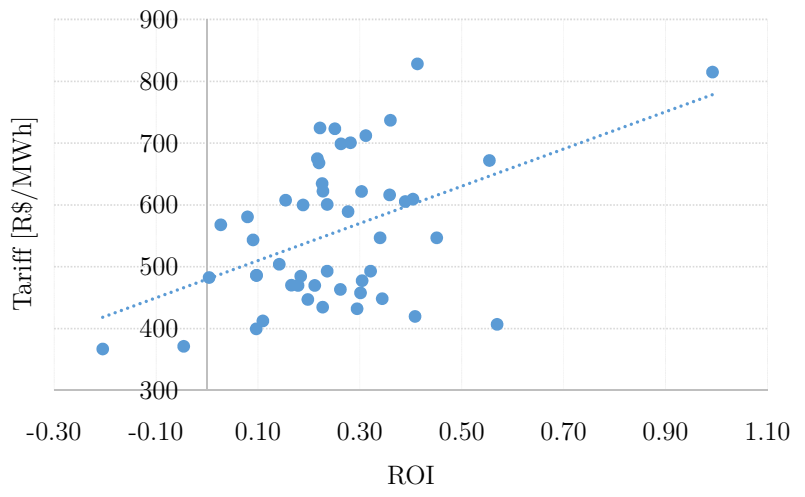

Fig. 7 Correlation between Return over Investment and the Tariff before DisCos optimization.

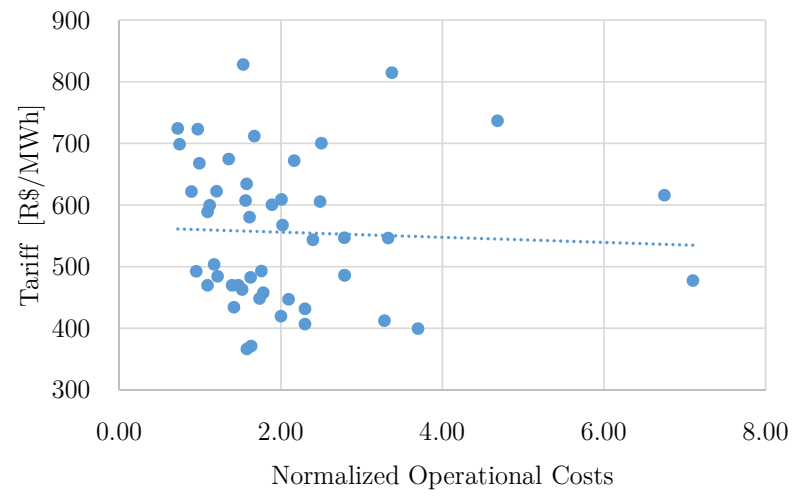

Fig. 8 Correlation between Normalized Operational Costs and the Tariff before DisCos optimization.

and Table 1. The last tariff processes of the Brazilian Utility Companies (Cortez (2018)) are presented in Table 1, including the Company Process (State), the Real and the Optimal Tariff $[R \$ / M W h]$ and the Real EVA $[M R \$]$. Bigger companies have higher revenues and, therefore, it is not accurate to compare the companies due to the absolute value of EVA. In order to solve this issue one can use the Return over Investment $(R O I)$ defined in Eq. 6, since it gives a normalized financial result for each company. The graphic of Fig. 7 shows a correlation of $46,13 \%$ between the values of $R O I$ and $T$.

Also, one can normalize the operational cost of the companies as it is done for ROI (13). The correlation found between $N \$ O p$ and $T$ is of $-2,67 \%$, as shown in the graphic of the Fig. 8. These two graphics indicate that the higher tariff is more related with higher profits than with higher costs.

$N \$ O p=\frac{\$ \text { Operational Costs }}{B}$

\subsection{Network Investment in the Grid by the DisCos}

After the optimization of the tariff using the regulatory assumptions, one can compare the value for the network in- 
vestment using the original data $(B)$ and the optimized one $\left(B^{*}\right)$. It is found that only $6(12 \%)$ companies are currently operating at an optimal investment value. It is alarming the high number of over-invested companies, $36(74 \%)$. And 7 (14\%) are under-invested, as shown in Fig. 9. This fact explains why high electricity tariffs are more related with higher profits than with higher costs: over-investments $(B>>$ $B^{*}$ ) with the aims to maximize profit for the shareholders, against the regulatory premises of maximizing the socioeconomic welfare, through a fare tariff for all.

The regulatory premises proposed by ANEEL seem to be fair for all market agents, and they are formally expressed in the concession contracts with typically 30 years period (which is a guarantee of market share), signed by all distribution companies. The problem for the managers of the DisCos seems to be complying with all the complexities and dynamics of the electricity market regulation, together with all the uncertainties in the countrys economical and political scenario, and under the constant pressures from international shareholders to maximize profits, no matter what happens internally. Representatives of the DisCos may create lobbies to promote changes in regulations in order to balance the business risks. However, the regulation itself becomes an asset by guaranteeing the companies financial economic equilibrium (FEE) with a specified WACC throughout tariffs increases. Therefore, operational efficiency through costs minimization is not as effective as financial efficiency through over-investments $(B)$ in the grid, which capital yield $(Y)$ can be recognized in the tariff revision process and are directly transferred to the tariffs, which are paid by the final customers. Moreover, the diversity and information asymmetry among DisCos and ANEEL in such a big country, makes that the technical-economical regulation is not an easy task for the regulatory agency as well.

The authors intended to show in this work that by using the Tariff Optimization Model (TAROT) to represent economic flows in the Brazilian regulated electricity market, the agents and their respective aggregated economic values could be better revealed than by going through the more complex and detailed regulatory procedures (PRORET) implemented by ANEEL. In fact, having a view of the whole picture of this game is not an easy task. Therefore, engineers working in a distribution company, researchers and students in academia, regulators and policy makers can benefit from the use of TAROT. The TAROT was originally created by Prof. Hector Arango at UNIFEI - The Federal University of Itajubá in collaboration with Professors from USP - The University of São Paulo during the evolution of the regulatory changes in the Brazilian electricity sector. The TAROT proved useful for conceptual as well as practical researches with Distribution Companies in Brazil. More easily it has become a didactic model to teach students about the regulatory and economic premises used by ANEEL in Brazil.

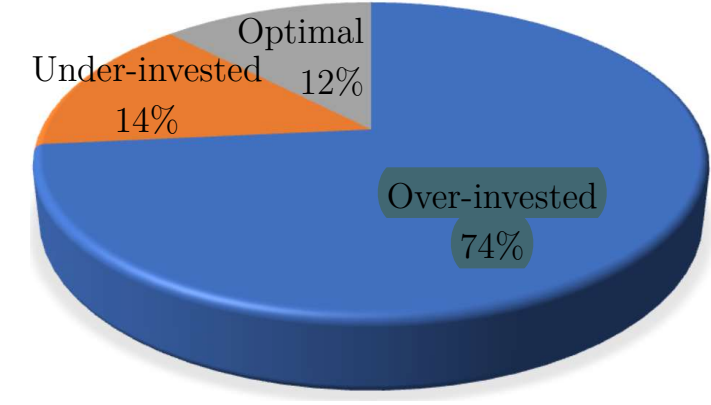

Fig. 9 Comparison of the original investment $B$ and the Optimal $B^{*}$.

However, as far as it is known, it has not been used in other countries, which may have distinct regulatory policies. This is not a limitation, but a potential for the use of the modeling principles.

\subsection{Aggregated Company for the whole country}

The idea of using the TAROT to represent a hypothetical Aggregated Company for the whole country, based on all the data from the distribution companies, can allow the simulation of distinct scenarios for optimization: regulatory optimization (maximize $E W A$, with $E V A=0$, resulting in a fair Tariff $T^{*}$ ); or $E V A$ optimization (in a "electricity market [environment] without regulation, i.e., only governed by capital owners and open market forces", including the consumers behavior, resulting in $E V A_{\max }, T_{\max }, E W A_{\min }$ ), This exercise, will show the flexibility of the TAROT model to be used for policy makers and regulators when designing the regulatory premises, as well as by any electricity market agent to evaluate the economic impact of policies on their respective economic aggregated values. Therefore the TAROT Model offers flexibility and generality to be applied to each DisCo or to an equivalent aggregated company representing a whole sector.

In order to have an economic and financial general overview of the Brazilian Power Distribution System, the data from all the DisCos were added and modeled in a unique aggregated company (AgDisCo). The input data is presented in Table 2.

The value for the energy tariff $(T)$ differs here from the average calculated in Section 4.1 because it is calculated using the total revenue divided by the total market.

The operational costs are shown in Table 3. From Fig.10, it is possible to note that almost $50 \%$ of the operational cost is used in the purchase of bulk electricity, $11 \%$ with connections and use of the Transmission and Distribution systems. The Sectorial Charges are those defined in the legislation representing a burden of $22 \%$. Over $16 \%$ of the expenses include administration, operational and maintenance costs.

Besides, it is noticed from Table 3 that over $18 \%$ of the energy purchased by the DisCos is lost, which represents 
Table 2 Aggregated data from the 49 DisCos.

\begin{tabular}{rrl}
\hline Elasticity $-\varepsilon$ & 14.82 & $\%$ \\
Tax rate on sales $-\mu$ & 27.38 & $\%$ \\
Tax rate on profit $-t$ & 34.01 & $\%$ \\
Depreciation rate $-d$ & 3.85 & $\%$ \\
Remuneration rate $-r_{w}$ & 7.94 & $\%$ \\
$k$ & 15.89 & $\%$ \\
Total Revenue (readjusted) & $153,019.10$ & {$[\mathrm{GR} \$]$} \\
Market $-E$ & 416.74 & {$[\mathrm{TWh}]$} \\
Energy Tariff - $T$ & 505.64 & {$[\mathrm{R} \$ \mathrm{MWh}]$} \\
Regulatory Base for Assets $-B$ & $87,813.70$ & {$[\mathrm{MR} \$]$} \\
\hline
\end{tabular}

Table 3 Aggregated Operational Cost from the 49 DisCos in [MR\$].

\begin{tabular}{rr}
\hline Administration and O\&M & $21,694.70$ \\
Sectorial Charges & $28,956.90$ \\
Electric Power Purchase & $65,484.16$ \\
Transmission and Distribution & $14,579.65$ \\
Other Revenues & 848.51 \\
Others & $2,380.92$ \\
Total Operational Cost & $132,247.82$ \\
Electric Power Losses [TWh] & 67.00 \\
Total Losses Cost & $11,850.56$ \\
\hline
\end{tabular}

Transmission and

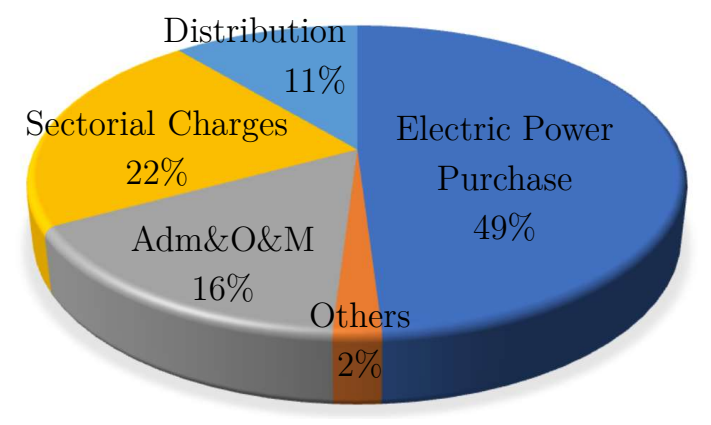

Fig. 10 Operational Costs.

Table 4 Parameters of AgDisCo

\begin{tabular}{rrl}
\hline Eagerness - $a$ & $3,916.58$ & {$[\mathrm{MR} \$ / \mathrm{TWh}]$} \\
Satiety $-b$ & 8.18 & {$\left[\mathrm{MR} \$ / \mathrm{TWh}^{2}\right]$} \\
Operational Cost Coef. $-e$ & 290.24 & {$[\mathrm{MR} \$ / \mathrm{TWh}]$} \\
Loss Coefficient $-p$ & $5,994.83$ & {$\left[\mathrm{MR}^{2} / T W h^{2}\right]$} \\
\hline
\end{tabular}

billions of Reais (approximately 3 billions of dollars annually).

With the original data, before optimization, from Tables 2 and 3 and using the TAROT formulation from Section 2 one can model the AgDisCo. The TAROT model and the calculated parameters are shown in 11 and Table 4, respectively.

The AgDisCo was optimized using the regulatory assumptions from Section 2.2. The calculated parameters and the TAROT model are shown in Table 5 and Fig. 12 , respectively. Note, by comparing the EWA values from Fig. 12 with the EWA value from Fig. 11, that the EWA- Economic

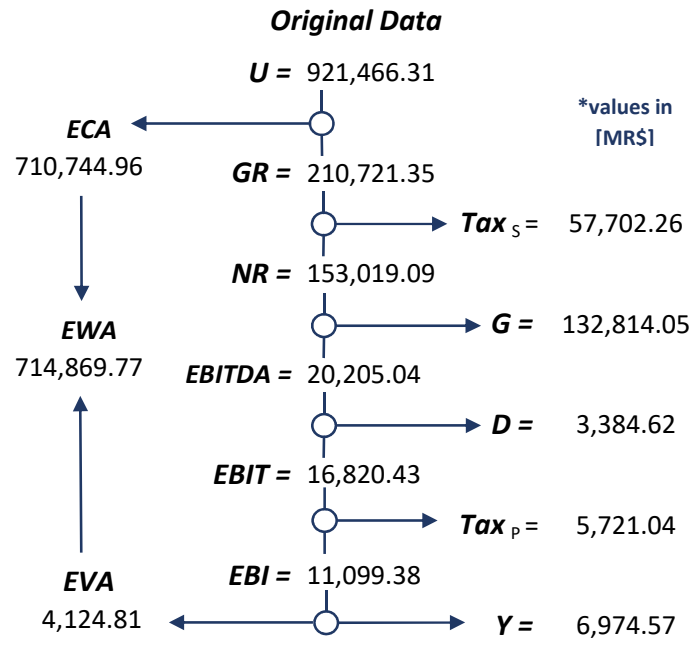

Fig. 11 TAROT for AgDisCo using the Original Data.

Table 5 Optimal TAROT for AgDisCo using Regulatory Assumptions.

\begin{tabular}{rrl}
\hline Optimal Price Tariff - $T^{*}$ & 419.30 & {$[\mathrm{R} \$ / \mathrm{MWh}]$} \\
Optimal Market - $E^{*}$ & 484.70 & {$[\mathrm{TWh}]$} \\
Optimal Investment - $B^{*}$ & $81,441.38$ & {$[\mathrm{MR} \$]$} \\
\hline
\end{tabular}

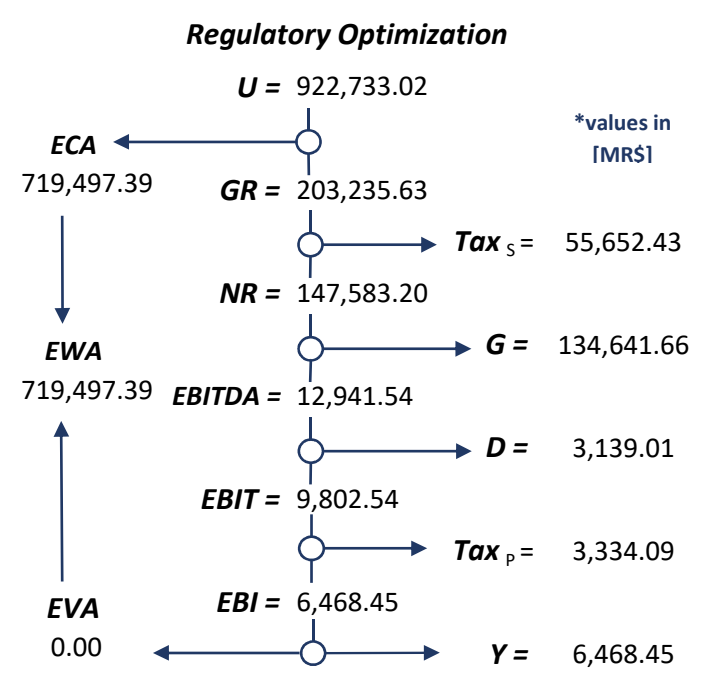

Fig. 12 Optimal TAROT for AgDisCo using Regulatory Assumptions.

Welfare Added to Society from this optimization is in the order of 4.6 billions of Reais, approximately, 1.09 billions of Dollars annually. In this optimized scenario, the Y or Capital Yield of the Aggregated Company is in the order of 6.4 billions of Reais, almost 1.52 billions of Dollars annually). From this perspective, one can get a broad overview of the electricity Brazilian Market, according to the premises used in this modelling. What really counts is that the optimization of the electricity sector strongly and positively affects the economy of a country, since it is in the base of Gross Domestic Product (GDP) production. 
Table 6 Optimal TAROT for AgDisCo using Profit Maximization's Assumptions.

\begin{tabular}{rrl}
\hline Optimal Price Tariff - $T^{\prime}$ & $2,137.70$ & {$[\mathrm{R} \$ / \mathrm{MWh}]$} \\
Optimal Market $-E^{\prime}$ & 217.34 & {$[\mathrm{TWh}]$} \\
\hline
\end{tabular}

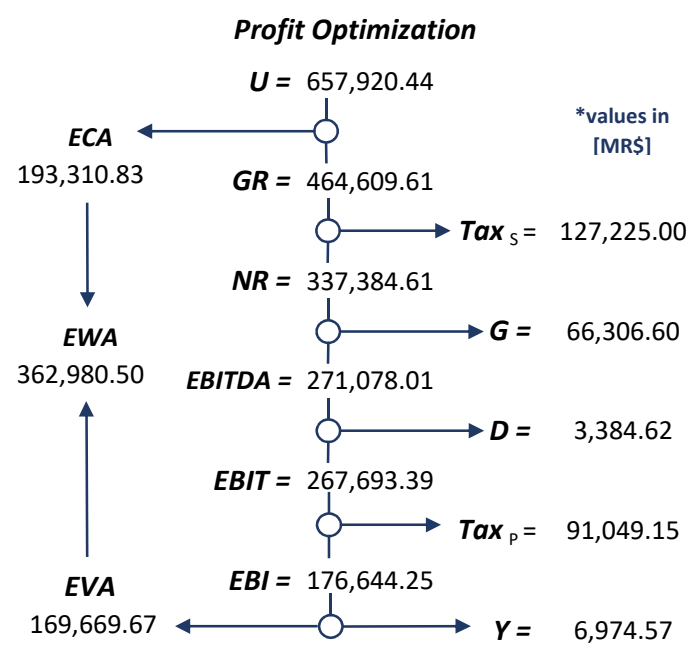

Fig. 13 Optimal TAROT for AgDisCo using Profit Maximization's Assumptions.

The AgDisCo was also optimized using the profit maximization assumptions from section 2.2. The calculated parameters and the TAROT model are shown in Table 6 and Fig. 13, respectively. Note now, by comparing the values with the ones from the previous scenario (12), that reversely, in an electricity market without regulation, i.e., only governed by capital owners and open market forces, the Tariff grows 4.4 times, the Energy Consumption reduces to half, but the EVA grows 41 times, and Government Taxes grows about 3.4 times, however the EWA reduces to half. That means more concentration of finances in shareholders and government hands and economic recession in the development of a country.

\section{Conclusions}

This work has presented an aggregated economic analysis of the Brazilian electricity distribution companies using an economic model of a regulated market. The economic flows of fundamental agents (consumer, power utility, government, society) were represented in the TAROT - Optimized Tariff Model, which was applied to the majority of the distribution companies in Brazil, based on public real data available from ANEEL - the Brazilian electrical energy regulatory agency. This has revealed their financial status in terms of over-investments ( $74 \%$ of the companies) or under-investments (14\% of the companies) compared to optimal investments (12\% of the companies) and positive (70\%), negative (12\%) or zero (18\%) economic value added (EVA) of each com- pany. Moreover, the model analysis showed the socioeconomic welfare added to society in face of different optimization objectives: maximizing the socioeconomic welfare added to society by the electricity market (max $E W A$, subjected to $E V A=0$ ) resulting in fare electricity tariffs, or maximizing the economical value added to shareholders of the company (maxEVA) resulting in even more high fares, high government taxes and lower electricity consumption causing economic recession.

The relevance of this work is its didactic yet coherent demonstration of the tariffs and the financial economic status of the Distribution Companies (DisCos), as well as of an equivalent whole aggregated company for Brazil. The novelty in applying the TAROT model is that all main market agents (consumer, power distribution company, government with the regulatory agency tariff revision process) and their economic fluxes are represented in the model. Then, the regulatory premises set by ANEEL (or any public policies impacting the electricity sector) can be evaluated qualitatively and quantitatively, aiming at the calculation of fare tariffs for all agents. For example, in order to maximize the socioeconomic welfare added $\left(E W A^{*}\right)$ by the electricity market, subjected to setting $E V A=0$ in every regulatory cycle (thus always guaranteeing a weighted average cost of capital (WACC) for the company), TAROT allows the calculation of the optimized investments $\left(B^{*}\right)$ for each power distribution company of the country. This reveals the financial economic status $(E V A<0, E V A \approx 0, E V A>0)$ of each company, as demonstrated along the paper, allowing actions to better planning and operation of the present power distribution market, which should operate with optimized tariffs $\left(T^{*}\right)$.

Therefore, it is a contribution to stimulate critical discussion about an economic issue, which is believed to be relevant to the public and to legislators, as well as to students, researchers and professional engineers in the power industry. Moreover, in order to design new market regulation and new business models for smart grids with distributed, renewable and energy storage resources, as well as to evaluate the impact of growing prosumers on the traditional electricity market, the TAROT model can be useful. But at first, it is fundamental the transparent comprehension of the current business and regulated market economic model. Otherwise, the market power trap mechanism can break any sustainable innovation in this sector.

Acknowledgements This study was financed in part by the Coordenaco de Aperfeicoamento de Pessoal de Nivel Superior - Brasil (CAPES) - Finance Code 001. The authors also gratefully acknowledge the financial support in part of CNPq, INERGE, and FAPEMIG, and express gratitude for the educational support of UNIFEI, KIOS Research and Innovation Center of Excellence and Department of Electrical and Computer Engineering, University of Cyprus and Universitat Politècnica de Catalunya. 


\section{References}

Alvarez LF (2007) Brazilian Discos Price Cap Regulation. In: 2007 IEEE Power Engineering Society General Meeting, IEEE, pp 1-6, DOI 10.1109/PES.2007.385944, URL http://ieeexplore.iee.org/document/4275710/

ANEEL (2015) $\quad$ Technical Report $\mathrm{n}^{\mathrm{o}}$ 22/2015-SGT/ANEEL. Tech. rep., URL http://www2.aneel.gov.br/aplicacoes/audiencia/arquivo/2014/023/resu

ANEEL (2016) Tariff Adjustment Procedures - PRORET. Tech. rep., URL http://www.aneel.gov.br/procedimentos-de-regulacaotarifaria-proret

ANEEL (2017a) ANEEL autoriza o agrupamento de concessões do grupo CPFL. URL http://www.aneel.gov.br/sala-de-imprensaexibicao-2/-/asset ${ }_{p}$ ublisher/zXQREz8EVIZ6/content/aneel autoriza-o-agrupamento - de - concessoes - do-grupocpfl/656877?inheritRedirect $=$ false

ANEEL (2017b) Schedule and Results of Tariff Distribution Processes. Tech. rep., URL http://www.aneel.gov.br/resultado-dosprocessos-tarifarios-de-distribuicao

ANEEL (2018) Distribution and Consumption Reports. Tech. rep., URL http://www.aneel.gov.br/relatorios-de-consumo-e-receita

Arango H, Abreu JPG, Bonatto BD, Kagan N, Tahan CMV, Gouvea MR (2008) A model for electricity markets: The impact of regulation on value. In: 2008 5th International Conference on the European Electricity Market, IEEE, pp 1-6, DOI 10.1109/EEM.2008.4579028, URL http://ieeexplore.iee.org/document/4579028/

Arango H, Donizeti B, de Abreu JPG, Vieira Tah CM (2011) The Impact of Power Quality on the Economy of Electricity Markets. In: Power Quality, InTech, DOI 10.5772/13933, URL http://www.intechopen.com/books/power-quality/the-impact-ofpower-quality-on-the-economy-of-electricity-markets

Arango LG, Deccache E, Bonatto BD, Arango H, Pamplona EO (2017) Study of Electricity Theft Impact on the Economy of a Regulated Electricity Company. Journal of Control, Automation and Electrical Systems 28(4):567-575, DOI 10.1007/s40313-017-0325-z, URL https://doi.org/10.1007/s40313-017-0325-z

Arango LG, Arango H, Deccache E, Bonatto BD, Pamplona EO (2019) Economic Evaluation of Regulatory Tariff Risk Planning for an Electric Power Company. Journal of Control, Automation and Electrical Systems 30(2):292-300, DOI 10.1007/s40313018-00437-8, URL http://link.springer.com/10.1007/s40313-01800437-8

Arango S, Dyner I, Larsen ER (2006) Lessons from deregulation: Understanding electricity markets in South America. Utilities Policy 14(3):196-207, DOI 10.1016/j.jup.2006.02.001, URL https://linkinghub.elsevier.com/retrieve/pii/S0957178706000130

Cortez C (2018) Development of Stochastic TAROT Economic Model for Economic Analysis of an Electrical Energy Regulated Distribuition Company. Tech. rep., Master's Dissertation of the Graduate Program in Electrical Engineering. Federal University of Itajubá, URL https://repositorio.unifei.edu.br/xmlui/handle/123456789/1486

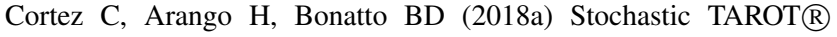
model: Stocastic economic market model for risk evaluation of a regulated electricity distribution company. In: 2018 Simposio Brasileiro de Sistemas Eletricos (SBSE), IEEE, pp 1-6, DOI 10.1109/SBSE.2018.8395700, URL https://ieeexplore.ieee.org/document/8395700/

Cortez C, Arango H, Bonatto BD (2018b) Study case of the

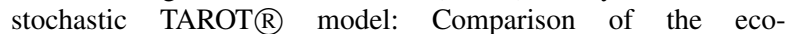
nomic performance of Brazilian Electric Power Distribution Companies considering the inherent risks of the sector. In: Simposio Brasileiro de Sistemas Eletricos (SBSE), IEEE, pp 1-6, DOI 10.1109/SBSE.2018.8395729, URL https://ieeexplore.ieee.org/document/8395729/

Costa MA, Mineti LB, Mayrink VD, Lopes ALM (2019) Bayesian detection of clusters in efficiency score maps: An application to Brazilian energy regulation. Applied Mathematical Modelling 68:66-81, DOI 10.1016/j.apm.2018.11.009, URL https://linkinghub.elsevier.com/retrieve/pii/S0307904X18305365

Cullmann A, Nieswand M (2016) Regulation and investment incentives in electricity distribution: An empirical assessment. Energy

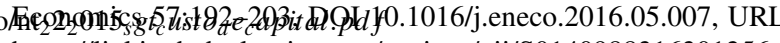
https://linkinghub.elsevier.com/retrieve/pii/S0140988316301256

Energisa Sul-Sudeste (2017) Relatório da Administração e Demonstrações Financeiras de 2017. Tech. rep., URL https://ri.energisa.com.br/enu/8355/Relatrio2017 SS.pdf

Homrich MC, Dorion E, Camargo ME, Olea PM, Cruz MR (2012) Forecast models and the nature of the decision process: The case of a Brazilian electricity distribution company. In: Proceedings of the 6th International Conference on Management of Innovation \& Technology (ICMIT), IEEE, Sanur Bali, Indonesia, pp 173-178, DOI 10.1109/ICMIT.2012.6225800, URL http://ieeexplore.ieee.org/document/6225800/

Jardini JA, Ramos DS, Martini JSC, Reis LB, Tahan CMA (2002) Brazilian Energy Crisis. IEEE Power Engineering Review 22(4):21-24, DOI 10.1109/MPER.2002.994845, URL http://ieeexplore.ieee.org/document/994845/

Jehle GA, Reny PJ (2001) Advance Microeconomic Theory. Addison Wesley Longman

Joskow P (2008) Lessons Learned from Electricity Market Liberalization. The Energy Journal 29:9-42, DOI 10.5547/ISSN0195-6574EJ-Vol29-NoSI2-3

Medina Macaira P, Castro Sousa R, Cyrino Oliveira FL (2016) Forecasting Brazil's electricity consumption with Pegels Exponential Smoothing Techniques. IEEE Latin America Transactions 14(3):1252-1258, DOI 10.1109/TLA.2016.7459606, URL http://ieeexplore.ieee.org/document/7459606/

Pereira LC, de Almeida TD (2013) Implementation of an economic model for the electricity market evaluation of public policies in smart grids. In: Proceedings of the Conference on Innovative Smart Grid Technologies (ISGT Latin America), IEEE/PES, Sao Paulo, Brazil, pp 1-4, DOI 10.1109/ISGT-LA.2013.6554397, URL http://ieeexplore.ieee.org/document/6554397/

Pereira LC, Lusvarghi SADS, Arango LG, Arango H, Bonatto BD (2015) Socioeconomic analysis of incentive public policies for the use of renewable energy per consumer class in Brazil. In: Proceedings of the Innovative Smart Grid Technologies Latin America (ISGT LATAM), IEEE/PES, Montevideo, Uruguay, pp 57-62, DOI 10.1109/ISGT-LA.2015.7381130, URL http://ieeexplore.ieee.org/document/7381130/

Pereira M, Barroso L, Rosenblatt J (2004) Supply adequacy in the brazilian power market. In: IEEE Power Engineering Society General Meeting, 2004., IEEE, vol 2, pp 1016-1021, DOI 10.1109/PES.2004.1372991, URL http://ieeexplore.ieee.org/document/1372991/

Scalzer RS, Rodrigues A, Macedo MS, Wanke P (2019) Financial distress in electricity distributors from the perspective of Brazilian regulation. Energy Policy 125:250-259, DOI 10.1016/j.enpol.2018.10.018, URL https://linkinghub.elsevier.com/retrieve/pii/S0301421518306724 